\title{
Identification of antibody reactive proteins in pancreatic cancer using 2D immunoblotting and mass spectrometry
}

\author{
MARZIEH REZAEI $^{1,2}$, SAMAN NIKEGHBALIAN $^{3}$, ZAHRA MOJTAHEDI $^{1}$ and ABBAS GHADERI ${ }^{1,2}$ \\ ${ }^{1}$ Shiraz Institute for Cancer Research, Shiraz University of Medical Sciences; \\ ${ }^{2}$ Department of Immunology, School of Medicine, Shiraz University of Medical Sciences; \\ ${ }^{3}$ Department of Surgery, Namazi Hospital, Shiraz University of Medical Sciences, Shiraz, Iran
}

Received May 27, 2017; Accepted January 25, 2018

DOI: $10.3892 /$ or.2018.6285

\begin{abstract}
Pancreatic ductal adenocarcinoma (PDAC) is a highly aggressive malignancy characterized by early invasiveness and resistance to treatment. Surgery in early stages is the only effective treatment, thus finding new biomarkers for the early detection of PDAC remains a major challenge. The present study aimed to compare the immunoproteome between PDAC patients and healthy controls using serological proteome analysis method. Firstly, cell lysates from two different pancreatic cancer cell lines were separated by two dimensional (2D) gels, and then transferred onto membranes probed with sera from 20 PDAC patients and 10 healthy controls. Proteins differentially reacting with autoantibodies in PDAC patients and control groups and were identified using mass spectrometry. This process led to the identification of 18 pancreatic immunoreactive antigens such as laminin, superoxide dismutase, ATP synthase, Rho GDP-dissociation inhibitor II, septin, glyceraldehyde 3-phosphate-dehydrogenase, phosphoglycerate mutase $\mathrm{B}$, tubulin $\beta 8$ channel and prohibit in. In the present study, we identified 18 immunoreactive proteins in PDAC. While the identified proteins were critically involved in PDAC pathogenesis, further investigation in a large scale population will determine the applicability of these potential biomarkers for the early diagnosis or treatment of the disease.
\end{abstract}

\section{Introduction}

Pancreatic ductal adenocarcinoma (PDAC) is the fourth leading cause of cancer-related death with a 5-year survival rate of $2 \%$ and a median survival rate of less than 6 months (1).

Correspondence to: Dr Abbas Ghaderi or Dr Zahra Mojtahedi, Shiraz Institute for Cancer Research, Shiraz University of Medical Sciences, Shiraz, P.O. Box: 71345-3119, Iran

E-mail: ghaderia@sums.ac.ir

E-mail: mojtahediz@sums.ac.ir

Key words: pancreatic ductal adenocarcinoma, SERPA, biomarker, autoantibody
Despite vast efforts by researchers, the mortality rate of PDAC patients remains almost equal to the incidence rate, due to metastasis during the early asymptomatic stages. Surgery in the early stages, before metastasis, is the only effective treatment. Thus, diagnosis of PDAC in early stages is extremely important and finding new biomarkers seems to be an urgent need (2).

Blood is the ideal biological specimen for detecting disease biomarkers, due to its availability. Furthermore, blood biomarkers demonstrate a high degree of accuracy, sensitivity and specificity, discriminate between harmless and aggressive lesions and can be detected in early curable stages with convenient and fast methods (3). Circulating autoantibodies are a group of serum biomarkers that are produced in response to tumor microenvironment alterations, such as mutated, overexpressed and aberrantly glycosylated or localized proteins. The stability of the autoantibodies compared to proteins and most importantly, the possibility of being early detected, before clinical symptoms and signs, are examples of the advantages of these markers (4). Autoantibodies can be detectable in the sera of patients, even before detecting tumor-associated antigens (TAA) and used as a disease-state reporter to identify the antigenic and physiological changes during the development and progression of the tumor (5).

Serological proteome analysis (SERPA), also called twodimensional (2D) western blot analysis, is a high-throughput technique for the identification of tumor antigens, in which cell lysates are firstly separated by 2D gels, and then transferred onto the membranes and probed with sera. Subsequently, reacting proteins are identified by mass spectrometry (MS). Using the 2D western blotting approach or other immunoproteomic approaches, numerous studies have evaluated and compared the panel of autoantibodies in healthy individuals and cancer patients against TAAs (6). The presence of autoantibodies against several proteins, such as p53, MUC1, recombination factor Rad51, insulin and $\beta$-islet cell proteins, calreticulin isoforms, phosphorylated $\alpha$-enolase (ENO), as well as DEAD-box protein 48 has been observed in $\operatorname{PDAC}(7,8)$. For example, Tomaino et al (9) found autoantibodies to ENO as a hallmark of PDAC. Their data specified that ENO1 was involved in PDAC cell invasion and that the administration of an anti-ENO1 mAb can be exploited as a novel therapeutic option to increase the survival of patients with metastatic 
PDAC. In this setting, the combination of elevated CA 19-9 serum levels and anti-ENOA1 autoantibodies improved the diagnostic value of CA 19-9 and resulted in diagnostic accuracy of 95\% (CA 19-9 is the only FDA-approved blood test for PDAC) (10).

Considering the scarcity of the published studies on the immunoproteome of PDAC patients, the aim of the present study was to compare the immunoproteome between PDAC patients and healthy controls. In order to achieve this goal, we selected two cancer cell lines, as the antigen source to exploit the autoantibody repertoire of pancreatic cancer (PC) patients. The screening of autoantibodies was performed using 2D western blot analysis with sera from PDAC patients, followed by subsequent identification of the target proteins by mass spectrometry. This process led to the identification of a number of new pancreatic immunoreactive antigens.

\section{Materials and methods}

Sera specimens. The present study was approved by the Ethics Committee of Shiraz University of Medical Sciences. Patients and controls were informed that their blood samples would be used for research and their written consent was obtained. The PDAC patients were recruited from the Surgery Department of Nemazi Hospital (Shiraz, Iran) during 18 months. Blood samples were collected prior to surgery or any other treatment. The diagnosis of PDAC was confirmed by histological analysis. None of the patients had distant metastasis at the time of diagnosis. The clinical features of the 20 newly diagnosed PDAC patients (male, 11; female, 9; median age, 60.2 \pm 9.9 years), are described in Table I. The sera from the 20 PDAC patients, were tested. The control group consisted of 10 healthy volunteers (male, 7; female, 3; median age, 60.4 \pm 8.9 years) who were recruited at a local Blood Transfusion Center. They had no history of cancer or autoimmunity. The samples were isolated from venous blood and stored at $-80^{\circ} \mathrm{C}$ until use.

Cell culture. The human PC cell lines Patu-8902 and Faraz-ICR were used in this study as antigen sources. Patu-8902, a PC cell line with full epithelial differentiation and high metastatic potential (11), was purchased from the Pasteur Institute of Iran (Tehran, Iran). Faraz-ICR is a PC cell line that was newly established in the Shiraz Institute for Cancer Research (Shiraz, Iran). Faraz-ICR has an epithelial-like nature and is in an undifferentiated state with partial aspects of epithelialmesenchymal transition and with significant higher migration ability than the Patu-8902 cells. Other characteristics of the Faraz-ICR cell line have been previously described (12). Cell lines were cultured in Dulbecco's modified Eagle's medium (DMEM; Gibco; Thermo Fisher Scientific, Carlsbad, CA, USA) supplemented with $10 \%$ fetal bovine serum (FBS; Gibco; Thermo Fisher Scientific) and $1 \%$ penicillin-streptomycin at $37^{\circ} \mathrm{C}$ in a $5 \% \mathrm{CO}_{2}$ atmosphere.

Sample preparation and two-dimensional gel electrophoresis $(2-D E)$. Sample preparations and 2-DE were performed according to methods previously described (6). Briefly, cells at a confluency of $70-80 \%$ were harvested using a solution of $0.25 \%$ Trypsin-EDTA (Gibco/Thermo Fisher Scientific Carlsbad, CA, USA). The detached cells were washed and lysed
Table I. Clinical features of the 20 PDAC patients.

\begin{tabular}{|c|c|c|c|c|}
\hline Patients & Sex & $\begin{array}{c}\text { Age } \\
\text { (years) }\end{array}$ & Stage & $\begin{array}{c}\text { Tumor } \\
\text { site }\end{array}$ \\
\hline $\mathrm{P} 1$ & Female & 61 & Well differentiated & Head \\
\hline P2 & Male & 58 & Well differentiated & Head \\
\hline P3 & Male & 70 & Well differentiated & Head \\
\hline P4 & Male & 65 & 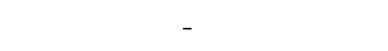 & Distal \\
\hline P5 & Male & 60 & Well differentiated & Head \\
\hline P6 & Female & 41 & - & Head \\
\hline P7 & Female & 60 & Moderately differentiated & Head \\
\hline P8 & Male & 53 & Well differentiated & Head \\
\hline P9 & Male & 64 & Well differentiated & Head \\
\hline P10 & Female & 60 & Poorly differentiated & Head \\
\hline P11 & Male & 83 & Well differentiated & Head \\
\hline $\mathrm{P} 12$ & Male & 58 & Moderately differentiated & Distal \\
\hline $\mathrm{P} 13$ & Male & 52 & - & - \\
\hline P14 & Male & 80 & Well differentiated & Head \\
\hline P15 & Female & 49 & - & Head \\
\hline P16 & Female & 67 & Well differentiated & Head \\
\hline P17 & Female & 52 & Well differentiated & Head \\
\hline P18 & Female & 63 & Well differentiated & Head \\
\hline P19 & Male & 52 & Well differentiated & Head \\
\hline $\mathrm{P} 20$ & Female & 58 & - & Head \\
\hline
\end{tabular}

in urea lysis buffer for $2 \mathrm{~h}$. The supernatants were collected and stored at $-80^{\circ} \mathrm{C}$. Protein concentration was determined using the Bradford assay protocol (13). The 2-DE analysis was performed in two steps. For the first dimension, $500 \mu \mathrm{g}$ protein lysate was loaded onto immobilized $\mathrm{pH}$ gradient strips (pH 3.0-10.0 NL; $18 \mathrm{~cm}$ ) (GE Healthcare, Uppsala, Sweden). For the second dimension, the strips were placed on the top of a $12 \%$ SDS polyacrylamide gel and run at a $30 \mathrm{~mA}$ constant current for $180 \mathrm{~min}$. After separation of proteins, the gels were visualized using a modified Coomassie Brilliant Blue (CBB) (Bio-Rad Laboratories, Hercules, CA, USA) staining method.

2Dwestern blot analysis. For the 2D western blot analysis. For the 2D western blotting, proteins from the 2D gels were transferred onto PVDF membranes by a semi-dry blotter (BioRad Laboratories, Hercules, CA, USA) at current of $1 \mathrm{~mA} / \mathrm{cm}^{2}$ of the membrane for $1 \mathrm{~h}$. The details of blocking, incubation with primary and secondary antibodies and washing steps were previously described (6). Finally, immunodetection was accomplished by incubation of the membranes in diaminobenzedene and $\mathrm{H}_{2} \mathrm{O}_{2}$ for 30 min.

Quantification of protein immunoreactivity and statistical analysis. The gels were scanned using a densitometer scanner (Bio-Rad Laboratories) at 300 dpi resolution and recorded in TIFF format. In order to map the spots with different immunoreactivity, we analyzed blots using the Prodigy software (version 1.0, Nonlinear Dynamics, Newcastle, UK). This software aligns and matches the images by placing 21 manual vectors followed by automatic vectors generated 


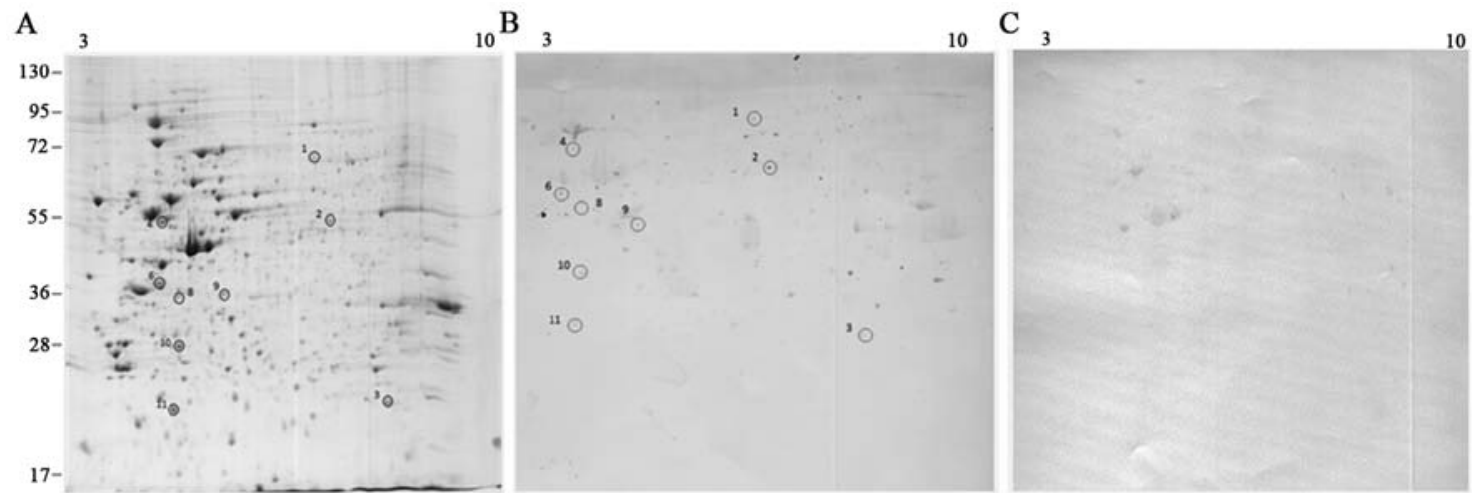

Figure 1. Representatives of Patu-8902 PC cell line 2D gels and blots. (A) Gel stained with Coomassie Blue. (B) Patu-8902 blot probed with sera from a pancreatic cancer patient. (C) Patu-8902 blot probed with sera from a healthy control. Blots were visualized by diaminobenzeden. The numbers in the gel and blots are the same as those in Table II.

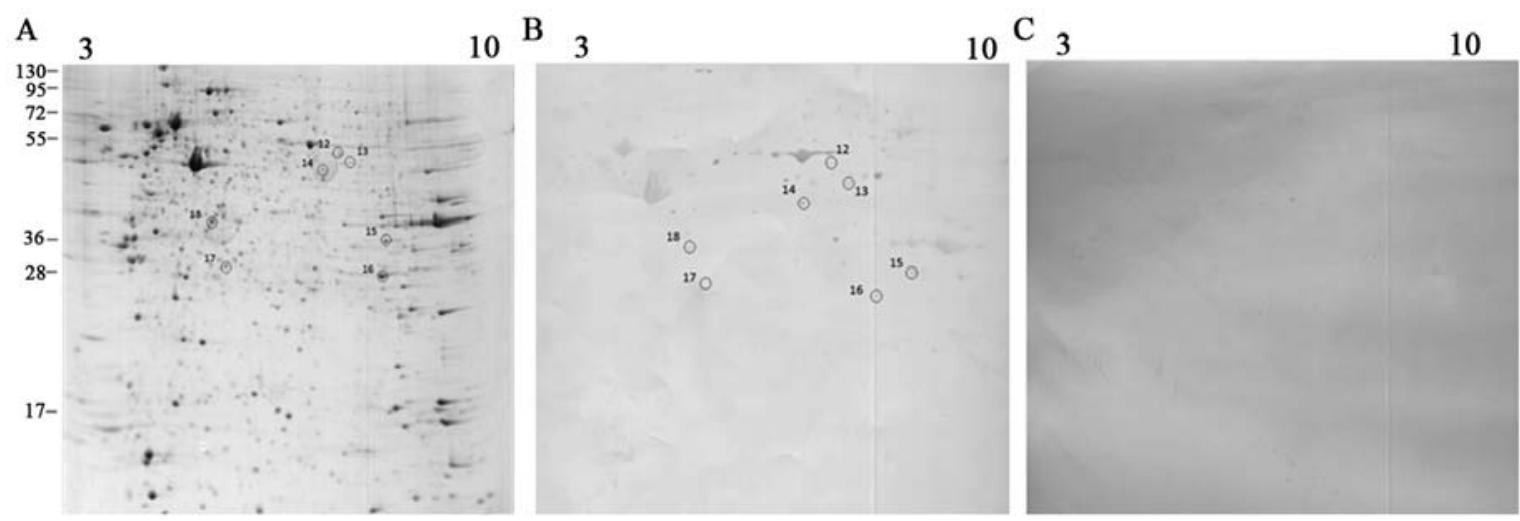

Figure 2. Representatives of Faraz-ICR PC cell line, 2D gels and blots. (A) Gel stained with Coomassie Blue. (B) Faraz-ICR blot probed with sera from a pancreatic cancer patient. (C) Faraz-ICR blot probed with sera from a healthy control. Blots were visualized by diaminobenzeden. The numbers in the gel and blots are the same as those in Table II.

by the software. The statistical differences in immunoreactive protein spots between PDAC patients and control groups were also calculated using the Prodigy software. The spots which exhibited a $>2$-fold increase in the average normalized volume between patient and control sera with a P-value $<0.05$ were considered as immunoreactive spots. P-values were calculated using Mann-Whitney $U$ test. The matching process and the differential immuneoreactivity of these spots were validated by eye in at least three images.

$M S$. Immunoreactive protein spots were manually cut from 2D gels derived from Patu-8902 and Faraz-ICR cell lysates and sent for MALDI-TOF/TOF MS (Ultraflex III; Bruker Daltonics, Bremen, Germany) analysis to the United Kingdom (Department of Biology, Proteomics and Analytical Biochemistry Laboratory, University of York, UK). The peptide mass fingerprinting (PMF) and tandem mass spectrometry (MS/MS) information were searched against the National Center for Biotechnology Information non-redundant (NCB Inr) database, using the Mascot search engine (Matrix Science, London, UK). One missed cleavage per peptide was permitted. Statistical confidence limits of $95 \%$ were applied for protein. MASCOT protein scores $>67$ were considered to indicate statistically significant difference $(\mathrm{P}<0.05)$.

\section{Results}

Proteins extracted from Patu-8902 and Faraz-ICR cell lines were subjected to isoelectric focusing followed by SDS-PAGE. Comparison of the whole cell proteome between the two cell lines revealed that, despite some similarities, their patterns shown certain differences (Figs. 1A and 2A) as we anticipated, because Patu-8902 is an epithelial cell line (11), however Faraz-ICR seems to be closer to mesenchymal cells (12). Therefore, using these two cell lines as a source of antigen, we expected to get distinct immunoreactive proteins to identify a wider range of heterogenic biomarkers in PC. There were shared immunoreactive proteins between these two cell lines, but with significant reactivity with normal sera that were not picked up from the gels for MS identification.

The 2D gels were transferred onto PVDF membranes and sera from 20 patients with PDAC and 10 healthy donors were individually screened for the presence of autoantibodies. The immunoblot pattern among patients revealed some differences but was highly reproducible for each patient. Protein spots that reacted at least by two-fold ratio (according to Prodigi software estimation) with at least three patient sera and generally had no visibility or with minimal reactivity with the control sera were sent for MS analysis. Fig. 3 displays the frequency 


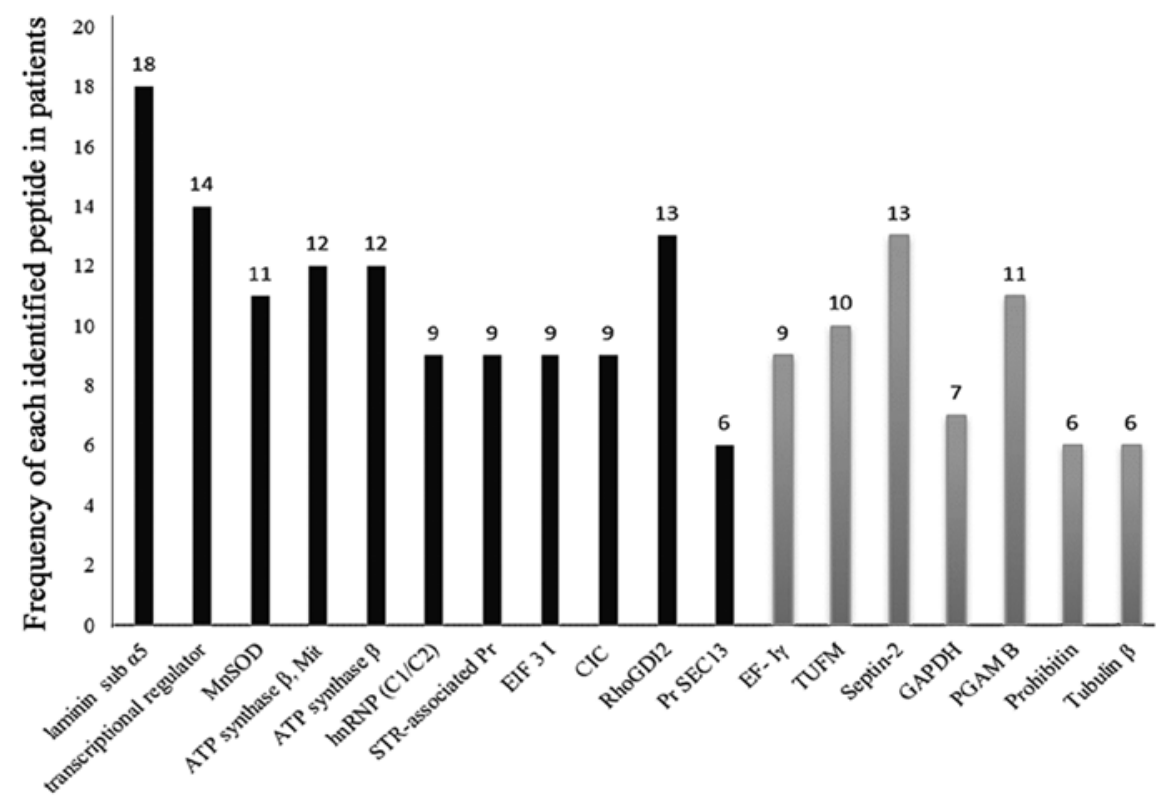

Peptide name

Figure 3. The frequency of each immunoreactive spot with patient sera. Black columns show immune reactivity with the Patu-8902 cell lysate and gray columns with the Faraz-ICR cell lysate.

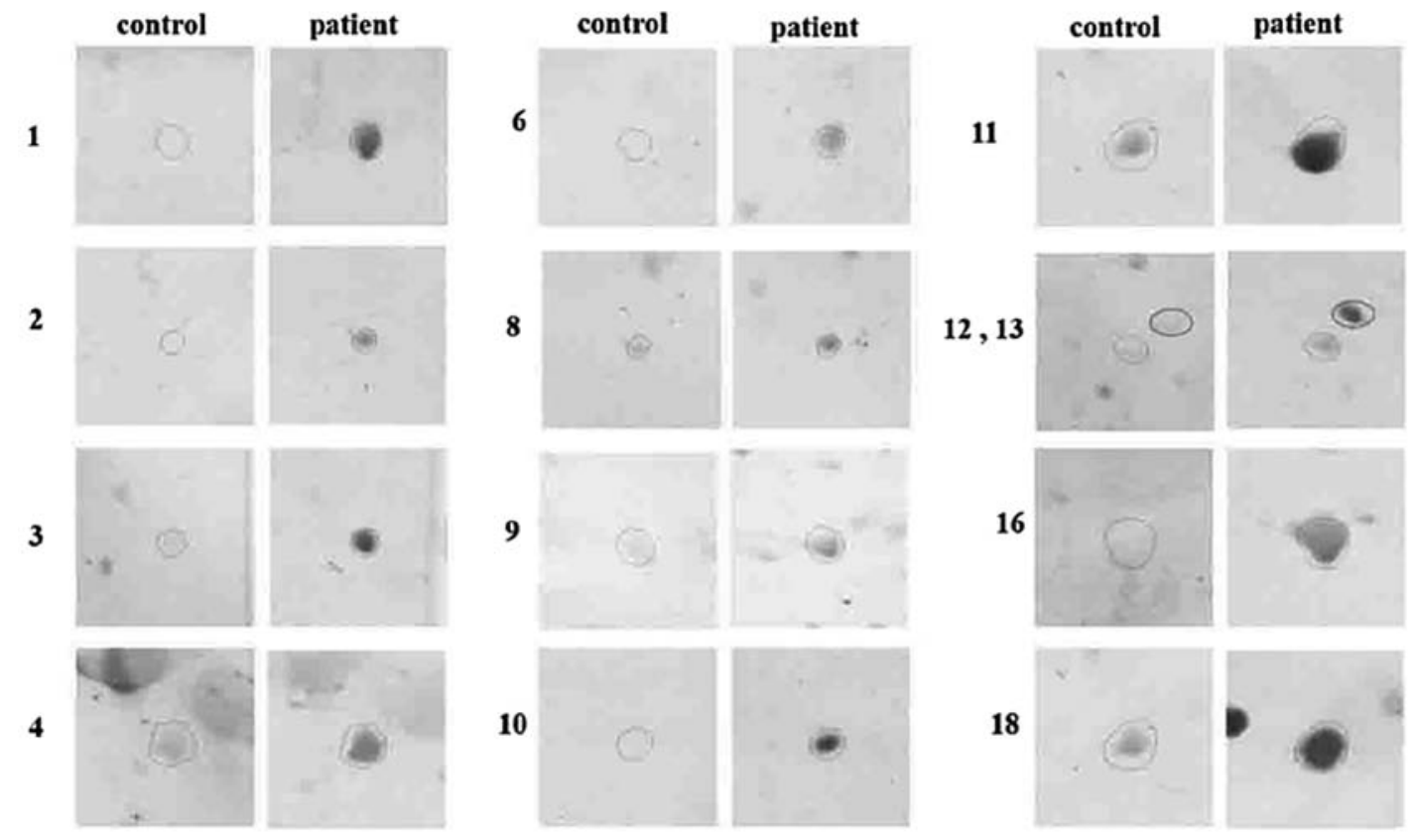

Figure 4. Enlarged sections of certain spots from Patu-8902 and Faraz-ICR 2D western blots probed with sera from pancreatic cancer patients and healthy individuals. The sections were automatically generated by the Prodigy software. The spot numbers are cross-referenced in Table II.

of patients with positive immunoreactivity for the identified spots. The enlarged views of some immunoreactive spots in patients and controls are displayed in Fig. 4.

The images of 2D gels and blots derived from Patu-8902 and Faraz-ICR cell lysates are displayed in Figs. 1 and 2. The descriptions of the identified proteins are shown in Table II. MS analysis identified two spots as the mixture of proteins. Protein numbers 4 and 5 were identified in the same spot (mitochondrial ATP synthase subunit $\beta$ and ATP synthase subunit $\beta$ ). Protein numbers 6 (heterogeneous nuclear ribonucleoproteins
$\mathrm{C} 1 / \mathrm{C} 2$ ) and 7 (serine-threonine kinase receptor-associated protein) were also identified in the same spot.

In total, 11 immune reactive proteins with Patu-8902 cell lysates were identified. Laminin subunit $\alpha-5$, transcriptional regulator, superoxide dismutase $[\mathrm{Mn}]$, mitochondrial, ATP synthase subunit $\beta$ and Rho GDP-dissociation inhibitor II were the spots which reacted with $>50 \%$ of the patient sera in Patu- 8902 blots. In this regard, laminin had the most frequency of reactivity with patient sera (18/20). Heterogeneous nuclear ribonucleoproteins $\mathrm{C} 1 / \mathrm{C} 2$, serine-threonine kinase 
Table II. Descriptions of the spots that had differential immunoreactivity with the sera of PDAC patients and control groups and were identified by mass spectrometry.

\begin{tabular}{|c|c|c|c|c|c|c|}
\hline & Protein name & $\begin{array}{c}\text { Accession } \\
\text { no. }\end{array}$ & $\begin{array}{c}\text { Molecular } \\
\text { weight }(\mathrm{kDa})\end{array}$ & $p \mathrm{I}$ & $\begin{array}{l}\text { Mascot } \\
\text { score }\end{array}$ & $\begin{array}{c}\text { No. of } \\
\text { matched peptides }\end{array}$ \\
\hline 1 & Laminin subunit $\alpha-5$ & gil1002609387 & 174.759 & 5.52 & 68 & 1 \\
\hline 2 & transcriptional regulator & gil291356655 & 54.090 & 9.54 & 72 & 1 \\
\hline 3 & Superoxide dismutase $(\mathrm{Mn})$, mitochondrial & gil30584207 & 25.019 & 8.94 & 102 & 1 \\
\hline 4 & ATP synthase subunit $\beta$, mitochondrial & XP_008323525.1 & 55.109 & 5.26 & 334 & 4 \\
\hline 5 & ATP synthase $\beta$ subunit, partial & AAZ30638.1 & 46045 & 5.22 & 251 & 3 \\
\hline 6 & Heterogeneous nuclear ribonucleoproteins $\mathrm{C} 1 / \mathrm{C} 2$ & gil8393544 & 34.421 & 4.95 & 73 & 1 \\
\hline 7 & Serine-threonine kinase receptor-associated protein & gil4063383 & 38.756 & 4.98 & 90 & 2 \\
\hline 8 & Protein SEC13 homolog & gil12805321 & 36.014 & 5.22 & 104 & 2 \\
\hline 9 & Eukaryotic translation initiation factor 3 subunit I & gil4503513 & 36.878 & 5.38 & 232 & 3 \\
\hline 10 & Chloride intracellular channel protein 1 & gil4588526 & 27.249 & 5.09 & 270 & 5 \\
\hline 11 & Rho GDP-dissociation inhibitor 2 & gil56676393 & 23.031 & 5.10 & 249 & 3 \\
\hline 12 & Elongation factor $\mathrm{I}-\gamma$ & gil51948418 & 50.371 & 6.31 & 120 & 3 \\
\hline 13 & Mitochondrial Ef-Tu, chain A & gil6137414 & 43.978 & 6.09 & 72 & 2 \\
\hline 14 & Septin 2 & gil16924010 & 41.737 & 6.15 & 115 & 3 \\
\hline 15 & glyceraldehyde 3-phosphate-dehydrogenase & gil56188 & 36.098 & 8.43 & 70 & 1 \\
\hline 16 & Phosphoglycerate mutase B isozyme & gil206101 & 28.685 & 6.20 & 91 & 1 \\
\hline 17 & Prohibitin isoform 1 & gil4505773 & 29.843 & 5.57 & 72 & 1 \\
\hline 18 & Tubulin $\beta 8$ channel & gil157383484 & 39.600 & 6.51 & 80 & 1 \\
\hline
\end{tabular}

Protein scores higher than 67 were considered to indicate a statistically significant difference $(\mathrm{P}<0.05)$. Spot numbers from 1 to 11 were cut from gels derived from Patu-8902 cells. Spot numbers from 11 to 18 were cut from gels derived from Faraz-ICR cells.

receptor-associated protein, eukaryotic translation initiation factor 3 subunit I, chloride intracellular channel protein I and protein SEC13 homolog reacted with $<50 \%$ of the patient sera. For each spot, the intensity of reactivity varied among patients; for example, the intensity of spot 1 (laminin subunit $\alpha-5$ ) was from 1.5- to 4.6-fold compared to the controls.

To identify possible different antigens, sera from PDAC patients were reacted against 2D blots derived from Faraz-ICR cell lysates. Seven proteins were identified, including elongation factor I- $\gamma$, mitochondrial Ef-Tu, septin 2, glyceraldehyde 3-phosphate-dehydrogenase (GAPDH), phosphoglycerate mutase $\mathrm{B}$ isozyme, prohibitin isoform $\mathrm{I}$ and tubulin $\beta 8$ channel. Among them, the autoantibody against septin 2 had the most frequency of reactivity with the patient sera.

\section{Discussion}

Circulating autoantibodies against TAAs may be useful for PC screening and diagnosis and help to detect molecular changes and cellular processes participating in the tumorigenesis pathways (14). However, current research in this area is still at an early stage, but the majority of examined autoantibodies as biomarkers showed a relative low sensitivity (85\% of autoantibodies demonstrated sensitivity of $<50 \%$ ) and high specificity ( $85 \%$ of autoantibodies demonstrated specificity of $\geq 90 \%$ ) (15).

Upregulation, isoform replacement, changes in cell distribution and aberrant or altered glycosylation of proteins can all stimulate the immune response toward autoantibody formation (16). We investigated the autoantibody repertoire in PDAC patients by the high-throughput technique of SERPA to identify the combination of biomarkers which is likely more sensitive and specific than a single biomarker because of the complexity and heterogeneity of the tumor (17). The immunoreactive proteins that we identified can be classified into extracellular matrix and cytoskeletal proteins, enzymes, chaperones, signal transduction proteins and transcriptional regulators (Table III).

The immunoreactive proteins from extracellular matrix (ECM) and cytoskeletal-associated proteins were laminin- $\alpha$, septin 2 and tubulin $\beta$. Various changes in these proteins have been identified in a wide variety of cancers (Table III). Immune response to cytoskeletal proteins in PDAC patients may be the reflection of a disturbed cytoskeletal structure. Tomaino et al (9) observed an antibody response to the cytoskeletal proteins cofilin-1 and keratin-type I cytoskeletal 10 in PC. Laminins are basement membrane (BM) proteins belonging to the glycoprotein family. They are composed of a heterotrimer of $\alpha, \beta$ and $\gamma$ polypeptide chains that through disulfide bonds shape a cross in the BM (18). Various combination of $\alpha, \beta$ and $\gamma$ chains form over 14 laminin isoforms. These isoforms have different distributions and functions in normal and transformed tissues. Isoforms 10,11 and 15 contain $\alpha 5$ chain and are the major laminin isoform among other variants involved in cell proliferation, migration, differentiation, and programmed cell death (19). Septins belong to a conserved family of GTP binding proteins that assemble into filaments and play a role in the process of membrane fusion during 
Table III. Aberrant expression of immunoreactive spots in different types of cancer.

\begin{tabular}{|c|c|c|c|c|}
\hline & Immunoreactive peptides & Alteration during transformation & Cancer type & (Refs.) \\
\hline \multirow[t]{3}{*}{ ECM and cytoskeletal } & Laminin & $\begin{array}{l}\text { Upregulation } \\
\text { abnormal glycosylation }\end{array}$ & Pancreas & (16) \\
\hline & Septin & Deregulation & $\begin{array}{l}\text { Oral/head and neck } \\
\text { Melanoma } \\
\text { Renal cell } \\
\text { Gastrointestinal } \\
\text { Pancreas } \\
\text { Hepatocellular }\end{array}$ & $(20)$ \\
\hline & Tubulin & $\begin{array}{l}\text { Altered expression of tubulin isotypes } \\
\text { Alterations in tubulin } \\
\text { post-translational modifications } \\
\text { Changes in the expression of } \\
\text { microtubule associated proteins }\end{array}$ & $\begin{array}{l}\text { Pancreas } \\
\text { Breast cancer } \\
\text { Neuroblastoma } \\
\text { Melanoma }\end{array}$ & $(21)$ \\
\hline \multirow[t]{7}{*}{ Enzymes } & ATP synthesis $\alpha$ subunit & Upregulation & Breast & $(43)$ \\
\hline & ATP synthesis $\beta$ subunit & Ectopic expression & $\begin{array}{l}\text { Lung } \\
\text { Prostate } \\
\text { Colon }\end{array}$ & $(27)$ \\
\hline & MnSOD & Upregulation & $\begin{array}{l}\text { Gastric and esophageal } \\
\text { Lung } \\
\text { Colorectal }\end{array}$ & $(28)$ \\
\hline & GAPDH & Deregulation & $\begin{array}{l}\text { Lung } \\
\text { Renal } \\
\text { Liver } \\
\text { Colorectal } \\
\text { Melanoma } \\
\text { Pancreas } \\
\text { Bladder } \\
\text { Thyroid }\end{array}$ & (26) \\
\hline & Rho-GDI2 & Overexpression & $\begin{array}{l}\text { Ovary } \\
\text { Gastric }\end{array}$ & $\begin{array}{l}(44) \\
(45)\end{array}$ \\
\hline & & Autoantibody production & $\begin{array}{l}\text { Ovary } \\
\text { Acute leukemia }\end{array}$ & $\begin{array}{l}(46) \\
(47)\end{array}$ \\
\hline & $\begin{array}{l}\text { Phosphoglycerate } \\
\text { mutase B isozyme }\end{array}$ & $\begin{array}{l}\text { Overexpression or } \\
\text { increased activity }\end{array}$ & $\begin{array}{l}\text { Colorectal } \\
\text { Liver } \\
\text { Lung } \\
\text { Breast } \\
\text { Brain }\end{array}$ & (34) \\
\hline \multirow[t]{4}{*}{$\begin{array}{l}\text { Transcriptional/ } \\
\text { translational proteins }\end{array}$} & $\begin{array}{l}\text { Heterogeneous nuclear } \\
\text { ribonucleoproteins } \mathrm{C} 1 / \mathrm{C} 2\end{array}$ & $\begin{array}{l}\text { Upregulation } \\
\text { Autoantibody production }\end{array}$ & $\begin{array}{l}\text { Hepatocellular } \\
\text { Pancreas } \\
\text { Ovary }\end{array}$ & $\begin{array}{l}(48) \\
(46)\end{array}$ \\
\hline & $\begin{array}{l}\text { Serine-threonine kinase } \\
\text { receptor-associated protein }\end{array}$ & $\begin{array}{l}\text { Ectopic expression } \\
\text { Upregulation } \\
\text { Autoantibody production }\end{array}$ & $\begin{array}{l}\text { Lung } \\
\text { Colorectal } \\
\text { Nasopharyngeal }\end{array}$ & (33) \\
\hline & Elongation factor & Overexpression of different subunits & $\begin{array}{l}\text { Colorectal } \\
\text { Gastric } \\
\text { Hepatocellular } \\
\text { Ovarian } \\
\text { Pancreas }\end{array}$ & (39) \\
\hline & $\begin{array}{l}\text { Mitochondrial Ef-Tu in } \\
\text { complex, chain A }\end{array}$ & Upregulation & Colorectal & $(40)$ \\
\hline
\end{tabular}


Table III. Continued.

\begin{tabular}{|c|c|c|c|c|}
\hline & Immunoreactive peptides & Alteration during transformation & Cancer type & (Refs.) \\
\hline Chaperones & Prohibitin & $\begin{array}{l}\text { Overexpression } \\
\text { Downregulation } \\
\text { Somatic mutation (SNP) } \\
\text { Trans+location } \\
\text { Shedding }\end{array}$ & $\begin{array}{l}\text { Cervix } \\
\text { Esophagus } \\
\text { Lung } \\
\text { Bladder } \\
\text { Ovary } \\
\text { Prostate } \\
\text { Glioma } \\
\text { Breast } \\
\text { Prostate } \\
\text { Colon }\end{array}$ & $(36)$ \\
\hline Membrane protein & $\begin{array}{l}\text { Chloride intracellular } \\
\text { channel Pr } 1\end{array}$ & Oncogenic protein & $\begin{array}{l}\text { Pancreas } \\
\text { Prostate } \\
\text { Colon } \\
\text { Gallblader } \\
\text { Gastric }\end{array}$ & $(38)$ \\
\hline
\end{tabular}

exocytosis (20). Microtubules are components of the cell cytoskeleton composed of $\alpha$ and $\beta$ tubulin heterodimers to form hollow cylindrical structures (21). Lee et al (22) revealed that high tubulin expression correlated with tumor stages in PDAC.

Metabolic reprogramming has been recognized as a hallmark of cancer, whereas knockdown or pharmacological inactivation of some enzymes results in increased cell apoptosis and retardation of tumor growth (23). ATP synthases, glyceraldehyde-3-phosphate dehydrogenase (GAPDH), Rho-GDP dissociation inhibitor 2, superoxide dismutase and serine-threonine kinase receptor-associated protein, are the immunoreactive enzymes identified in PDAC patients sera. Despite classification of these molecules as metabolic enzymes, they take part in other key processes within cells. For example, GAPDH, in addition to glycolytic effects, participates in DNA replication and repair, endocytosis, exocytosis, cytoskeletal organization, iron metabolism, carcinogenesis and cell death (24). GAPDH was regarded as the main housekeeping gene for expression quantification in tumors, however current studies indicated GAPDH deregulation in various tumors. Remarkably increased GAPDH levels are observed in many human cancer types and often correlate with reduced survival $(25,26)$. Among tumor markers, surface and secreted proteins play an important role. Some TAA through tumor transformation are dislocated in the cell surface. These molecules could be suitable targets for tumor therapy as they are absent on the surface of normal cells. Superoxide dismutase (SOD) and ATP synthases subunit $\beta$ are from mitochondria, but translocalization as well as their ectopic expression in the cell surface membrane of transformed cells have been proven $(27,28)$. The altered and elevated expression of mitochondrial form SOD (MnSOD) in different cancer cells has been observed (Table III) and correlated with increasing aggressiveness and poor prognosis while in PC the levels of this protein have been inversely associated with cell growth (29). MnSOD protects the cells against reactive oxygen species (ROS), ionizing radiation, and inflammatory cytokines and plays a role as a tumor suppressive protein (30). Its overexpression inhibits many of the typical properties of cancer such as cell proliferation, invasiveness and anchorageindependent cell growth (28). ATP synthase is constitutively expressed in the inner mitochondrial membrane in normal cells. Overexpression or ectopic appearance on the cell surface of its subunits ( $\alpha$ and $\beta$ ) is reported in breast cancer, colon and prostate carcinoma cells, as well as lung adenocarcinoma cell line. Therefore, it may act as a TAA during cancer progression (27).

Another immunoreactive protein identified in the present study was Rho GDP dissociation inhibitor 2 (RhoGDI2). The overexpression of RhoA and RhoC induce invasive behavior and metastatic activity to various tumor types (31). New findings indicate that RhoGDI2 by regulating the expression of key genes such as E-cadherin, Slug, Snail and $\alpha$-Smooth muscle actin both in in vivo and in vitro models suppressed the metastasis activity of lung cancer cells through EMT (32).

Serine-threonine kinase receptor-associated protein (STRAP) is an enzyme that through intervention in TGF- $\beta$ signaling promotes the growth and enhances the tumorigenicity. Tumor progression due to STRAP upregulation and the presence of autoantibody against STRAP in some tumors has been proven (33). Phosphoglycerate mutase 1 is an important enzyme in the aerobic glycolysis pathway. Several studies have revealed that Phosphoglycerate mutase 1 expression and its activity are increased in a variety of human malignancies (34).

Prohibitin is a conserved chaperone involved in proteins stabilization that regulates cell cycle progression, mitochondrial activity and cellular homeostasis. Between two transcripts, prohibitin1 exhibits more association with human cancers and has been identified as a potential prognostic biomarker in human PC (35). Various changes in prohibitin including overexpression, somatic mutation and trans-localization to cytoplasm and membrane rafts 
in different types of cancer (Table III) (36) are potential mechanisms that can stimulate the immune system and autoantibody production.

Protein SEC13 and chloride intracellular channel (CLIC) are two of the other candidates identified in the present study. They are both membrane proteins. Protein SEC13 is required for vesicle biogenesis from the endoplasmic reticulum during the transport of proteins. CLIC family constitutes a unique class of mammalian channel proteins that exist as both cytoplasm-soluble proteins and membrane-bound channels. By regulating the expression of integrin, CLIC is implicated in diverse biological processes such as apoptosis, differentiation, cell-cycle regulation and migration (37). Lu et al (38) revealed the involvement of CLIC1 in PC progression and aggressiveness and found that the classification of $\mathrm{PC}$ patients according to the expression of CLIC1 represented a valuable tool to identify PC patients with a poor prognosis.

Transcriptional regulator, heterogeneous nuclear ribonucleoproteins $\mathrm{Cl} / \mathrm{C} 2$ (hnRNP), eukaryotic translation initiation factor 3 subunit I (EIF3I), elongation factor (EF) and mitochondrial Ef-Tu (TUFM) are nucleus factors involved in transcription and translation. Overexpression of these compartments could lead to increased translation rate and overall protein synthesis. This may enhance cellular proliferation and reduce the time required for protein production in stimulated cancerous cells. Due to their important functions in cancer cell growth, these molecules can be targeted by chemotherapeutic agents (act as translation inhibitors) in rapidly growing tumor tissues (39) and their selective inhibition may present a new avenue for the targeted therapy of cancer (40). The expression level of EF-Tu in several types of cancers has been investigated and changes in its expression level were specified. Upregulation of both EF-Tu and the cytoplasmic elongation factor EF-1 $\alpha$ in PDAC patients has been reported (41).

Data obtained using high-throughput techniques are generally required to be validated by other methods. The generation of an autoantibody is usually the reflection of an aberrant expression of an autoantigen. Identified immunogenic proteins in 2D western blotting can be validated in terms of their aberrant expression, such as overexpression using immunohistochemistry. Furthermore, autoantibodies against identified autoantigens can be investigated in a larger number of patients using ELISA. Although further investigation is warranted, the present study identified eighteen potential PC biomarkers. Among the identified proteins, a combination of those with the most reactivity with patient sera, such as laminin and septin, are considered appropriate candidate biomarkers for future studies.

In conclusion, with the aim of identifying new biomarkers in PC, we investigated the autoantibody repertoire against TAAs in PC using a high-throughput method. Eighteen immune reactive proteins were identified. Some of them have been identified as PC biomarkers in prior studies, while others need to be further investigated in order to explore their applicability as widespread biomarkers in PC.

\section{Acknowledgements}

The present study was part of the PhD thesis of Marzieh Rezaei and was financially supported by Shiraz University of Medical
Sciences, Shiraz, Iran (grant no. 93-7197). This study was also financially supported by the Shiraz Institute for Cancer Research (grant no. ICR-100-508).

\section{Competing interests}

The authors declare that they have no competing interests.

\section{References}

1. Urayama S: Pancreatic cancer early detection: Expanding higherrisk group with clinical and metabolomics parameters. World $\mathrm{J}$ Gastroenterol 21: 1707, 2015.

2. Gräntzdörffer I, Carl-McGrath S, Ebert MP and Röcken C: Proteomics of pancreatic cancer. Pancreas 36: 329-336, 2008

3. Desmetz C, Mange A, Maudelonde T and Solassol J: Autoantibody signatures: Progress and perspectives for early cancer detection. J Cell Mol Med 15: 2013-2024, 2011.

4. Caron M, Choquet-Kastylevsky G and Joubert-Caron R: Cancer immunomics using autoantibody signatures for biomarker discovery. Mol Cell Proteomics 6: 1115-1122, 2007.

5. Dudas SP, Chatterjee M and Tainsky MA: Usage of cancer associated autoantibodies in the detection of disease. Cancer Biomark 6: 257-270, 2010.

6. MojtahediZ,Safaei A,YousefiZandGhaderi A:Immunoproteomics of HER2-positive and HER2-negative breast cancer patients with positive lymph nodes. OMICS 15: 409-418, 2011.

7. Xia Q, Kong XT, Zhang GA, Hou XJ, Qiang H and Zhong RQ: Proteomics-based identification of DEAD-box protein 48 as a novel autoantigen, a prospective serum marker for pancreatic cancer. Biochem Biophys Res Commun 330: 526-532, 2005.

8. Hong SH, Misek DE, Wang H, Puravs E, Giordano TJ, Greenson JK, Brenner DE, Simeone DM, Logsdon CD and Hanash SM: An autoantibody-mediated immune response to calreticulin isoforms in pancreatic cancer. Cancer Res 64: 5504-5510, 2004.

9. Tomaino B, Cappello P, Capello M, Fredolini C, Ponzetto A, Novarino A, Ciuffreda L, Bertetto O, De Angelis C, Gaia E, et al: Autoantibody signature in human ductal pancreatic adenocarcinoma. J Proteome Res 6: 4025-4031, 2007.

10. Principe M, Ceruti P, Shih NY, Chattaragada MS, Rolla S, Conti L, Bestagno M, Zentilin L, Yang SH, Migliorini P, et al: Targeting of surface alpha-enolase inhibits the invasiveness of pancreatic cancer cells. Oncotarget 6: 11098, 2015.

11. Elsässer HP, Lehr U, Agricola B and Kern HF: Structural analysis of a new highly metastatic cell line PaTu 8902 from a primary human pancreatic adenocarcinoma. Virchows Arch B Cell Pathol Incl Mol Pathol 64: 201-207, 1993.

12. Rezaei M, Hosseini A, Nikeghbalian S and Ghaderi A: Establishment and characterization of a new human acinar cell carcinoma cell line, faraz-ICR, from pancreas. Pancreatology 17: 303-309, 2017.

13. Okutucu B, Dınçer A, Habib Ö and Zıhnıglu F: Comparison of five methods for determination of total plasma protein concentration. J Biochem Biophys Methods 70: 709-711, 2007.

14. Casiano CA, Mediavilla-Varela M and Tan EM: Tumor-associated antigen arrays for the serological diagnosis of cancer. Mol Cell Proteomics 5: 1745-1759, 2006.

15. Dumstrei K, Chen $\mathrm{H}$ and Brenner $\mathrm{H}$ : A systematic review of serum autoantibodies as biomarkers for pancreatic cancer detection. Oncotarget 7: 11151, 2016.

16. Pan S, Brentnall TA and Chen R: Glycoproteins and glycoproteomics in pancreatic cancer. World J Gastroenterol 22: 9288-9299, 2016.

17. Li J, Wang LJ, Ying X, Han SX, Bai E, Zhang Y and Zhu Q: Immunodiagnostic value of combined detection of autoantibodies to tumor-associated antigens as biomarkers in pancreatic cancer. Scand J Immunol 75: 342-349, 2012.

18. Durbeej M: Laminins. Cell Tissue Res 339: 259-268, 2010.

19. Kikkawa Y, Sanzen N and Sekiguchi K: Isolation and characterization of laminin-10/11 secreted by human lung carcinoma cells laminin-10/11 mediates cell adhesion through integrin alpha3 beta1. J Biol Chem 273: 15854-15859, 1998.

20. Connolly D, Abdesselam I, Verdier-Pinard P and Montagna C: Septin roles in tumorigenesis. Biol Chem 392: 725-738, 2011.

21. Parker AL, Kavallaris M and McCarroll JA: Microtubules and their role in cellular stress in cancer. Front Oncol 4: 153, 2014. 
22. Lee KM, Cao D, Itami A, Pour PM, Hruban RH, Maitra A and Ouellette MM: Class III beta-tubulin, a marker of resistance to paclitaxel, is overexpressed in pancreatic ductal adenocarcinoma and intraepithelial neoplasia. Histopathology 51: 539-546, 2007.

23. Zhang D, Jin N, Sun W, Li X, Liu B, Xie Z, Qu J, Xu J, Yang X, $\mathrm{Su} \mathrm{Y}$, et al: Phosphoglycerate mutase 1 promotes cancer cell migration independent of its metabolic activity. Oncogene 36 : 2900-2909, 2017.

24. Colell A, Green DR and Ricci JE: Novel roles for GAPDH in cell death and carcinogenesis. Cell Death Differ 16: 1573-1581, 2009.

25. Guo C, Liu S and Sun MZ: Novel insight into the role of GAPDH playing in tumor. Clin Transl Oncol 15: 167-172, 2013.

26. Giusti L, Iacconi P, Ciregia F, Giannaccini G, Donatini GL, Basolo F, Miccoli P, Pinchera A and Lucacchini A: Fine-needle aspiration of thyroid nodules: Proteomic analysis to identify cancer biomarkers. J Proteome Res 7: 4079-4088, 2008.

27. Lu ZJ, Song QF, Jiang SS, Song Q, Wang W, Zhang GH, Kan B, Chen LJ, Yang JL, Luo F, et al: Identification of ATP synthase beta subunit (ATPB) on the cell surface as a non-small cell lung cancer (NSCLC) associated antigen. BMC Cancer 9: 16, 2009.

28. Borrelli A, Schiattarella A, Bonelli P, Tuccillo FM, Buonaguro FM and Mancini A: The functional role of MnSOD as a biomarker of human diseases and therapeutic potential of a new isoform of a human recombinant MnSOD. Biomed Res Int 2014: 476789, 2014.

29. Weydert C, Roling B, Liu J, Hinkhouse MM, Ritchie JM, Oberley LW and Cullen JJ: Suppression of the malignant phenotype in human pancreatic cancer cells by the overexpression of manganese superoxide dismutase. Mol Cancer Ther 2: 361-369, 2003

30. Liou GY and Storz P: Reactive oxygen species in cancer. Free Radic Res 44: 479-496, 2010.

31. Fujita A, Shida A, Fujioka S, Kurihara H, Okamoto T and Yanaga K: Clinical significance of Rho GDP dissociation inhibitor 2 in colorectal carcinoma. Int J Clin Oncol 17: 137-142, 2012.

32. Niu H, Wu B, Jiang H, Li H, Zhang Y, Peng Y and He P: Mechanisms of RhoGDI2 mediated lung cancer epithelialmesenchymal transition suppression. Cell Physiol Biochem 34 2007-2016, 2014

33. Halder SK, Anumanthan G, Maddula R, Mann J, Chytil A, Gonzalez AL, Washington MK, Moses HL, Beauchamp RD and Datta PK: Oncogenic function of a novel WD-domain protein, STRAP, in human carcinogenesis. Cancer Res 66: 6156-6166, 2006.

34. Jiang X, Sun Q, Li H, Li K and Ren X: The role of phosphoglycerate mutase 1 in tumor aerobic glycolysis and its potential therapeutic implications. Int J Cancer 135: 1991-1996, 2014.

35. Zhong N, Cui Y, Zhou X, Li T and Han J: Identification of prohibitin 1 as a potential prognostic biomarker in human pancreatic carcinoma using modified aqueous two-phase partition system combined with 2D-MALDI-TOF-TOF-MS/MS Tumor Biol 36: 1221-1231, 2015.
36. Leal MF, Cirilo PD, Mazzotti TK, Calcagno DQ, Wisnieski F, Demachki S, Martinez MC, Assumpção PP, Chammas R, Burbano RR and Smith MC: Prohibitin expression deregulation in gastric cancer is associated with the $3^{1}$ untranslated region $1630 \mathrm{C}>\mathrm{T}$ polymorphism and copy number variation. PloS One 9: e98583, 2014.

37. Tung JJ and Kitajewski J: Chloride intracellular channel 1 functions in endothelial cell growth and migration. J Angiogenes Res 2: 23, 2010.

38. Lu J, Dong Q, Zhang B, Wang X, Ye B, Zhang F, Song X, Gao G Mu J, Wang Z, et al: Chloride intracellular channel 1 (CLIC1) is activated and functions as an oncogene in pancreatic cancer. Med Oncol 32: 1-9, 2015

39. Al-Maghrebi M, Anim JT and Olalu AA: Up-regulation of eukaryotic elongation factor- 1 subunits in breast carcinoma. Anticancer Res 25: 2573-2577, 2005.

40. Shi H, Hayes M, Kirana C, Miller R, Keating J, MacartneyCoxson D, Stubbs R: TUFM is a potential new prognostic indicator for colorectal carcinoma. Pathology 44: 506-512, 2012.

41. Xu C, Wang J, Li J and Fang R: Expression of elongation factor (EF)-Tu is correlated with prognosis of gastric adenocarcinomas. Int J Mol Sci 12: 6645-6655, 2011.

42. Pan J, Sun LC, Tao YF, Zhou Z, Du XL, Peng L, Feng X, Wang J, Li YP, Liu L, et al: ATP synthase ecto- $\alpha$-subunit: A novel therapeutic target for breast cancer. J Transl Med 9: 211, 2011.

43. Tapper J, Kettunen E, Seppälä M, Andersson LC and Knuutila S: Changes in gene expression during progression of ovarian carcinoma. Cancer Genet Cytogenet 128: 1-6, 2001.

44. Cho HJ, Baek KE, Park SM, Kim IK, Choi YL, Cho HJ, Nam IK, Hwang EM, Park JY, Han JY, et al: RhoGDI2 expression is associated with tumor growth and malignant progression of gastric cancer. Clin Cancer Res 15: 2612-2619, 2009.

45. Yoneyama K, Kojima S, Kodani Y, Yamaguchi N, Igarashi A Kurose K, Kawase R, Takeshita T, Hattori S and Nagata K: Proteomic identification of autoantibodies in sera from patients with ovarian cancer as possible diagnostic biomarkers. Anticancer Res 35: 881-889, 2015.

46. Cui JW, Li WH, Wang J, Li AL, Li HY, Wang HX, He K, Li W, Kang LH, Yu M, et al: Proteomics-based identification of human acute leukemia antigens that induce humoral immune response. Mol Cell Proteomics 4: 1718-1724, 2005.

47. Yan-Sanders Y, Hammons GJ and Lyn-Cook BD: Increased expression of heterogeneous nuclear ribonucleoprotein A2/B1 (hnRNP) in pancreatic tissue from smokers and pancreatic tumor cells. Cancer Lett 183: 215-220, 2002. 